\title{
Nurses' Views on Need for Professional Development in Nepal
}

\author{
Shrestha GK,' Bhandari N, ${ }^{1}$ Singh B $^{2}$ \\ 'Department of Nursing, Kathmandu University School of Medical Sciences, ${ }^{2}$ Department of nursing, Kathmandu University Dhu- \\ likhel Hospital, Nepal.
}

\section{ABSTRACT}

Introduction: This study explores the nurses' views on need for professional development and barriers in Nepal.

Methods: This is a qualitative content analysis study conducted among nurses from different health institutes. In-depth interviews and focus group discussions were used to obtain their views on need of professional development and major barriers against professional development in Nepal. Eleven nurses for in-depth interviews and three groups of six nurses each for focus group discussions were selected purposefully from Kathmandu University Hospital, Dhulikhel and Tribhuban University Teachng Hospital, Kathmnadu.

Results: Five themes emerged from qualitative data. "Continuing professional development", "supportive management", "nursing leadership", "recognition and respect" and "professional networking" were considered as essential factors for professional development. Lack of "commitment by the nurses", "female gender professional" and "lack of autonomy" were felt as barriers for the nursing professioanl development.

Conclusions: Continuing professional development and supportive working environment are crucial to make nursing profession more dynamic and appealing in Nepal.

Keywords: continuing professional development, professional development, supportive managment

\section{INTRODUCTION}

Nurses play frontline role in all the health organizations. Despite being the largest group among health professionals, nursing still lacks strong models for assuring continuous competency and professional development. ${ }^{1,2}$

For the last five decades, nursing education has remained popular and respected. ${ }^{3}$ At present there are total 29,363 nurses registered in Nepal Nursing council. ${ }^{4}$ The increasing number of nurses has brought several challenges for professional development such as globalization, privatization of nursing education, mushrooming of nursing educational institutes without qualified trainers, poor working conditions, limited training environment, centralization of human resources, and mobility of the workforce. ${ }^{4}$ Similarly, continued rapid transitions are taking place in health care, workplace, and education which nurses must adapt to. ${ }^{2-5}$ Therefore, it is necessary to understand what these nurses know, 
Shrestha et al. Nurses' Views on Need for Professional Development in Nepal

feel and think about their professional development needs. Therefore, this study explores the nurses' views on need and barriers for professional development in Nepal.

\section{METHODS}

This is a qualitative content analysis study conducted among nurses from Kathmandu University Hospital, Dhulikhel and Tribhuvan University Teaching Hospital, Maharajgunj in the year 2010. The study participants included those who had service experience more than five years, currently full time working, Nepali citizen and willing to participate in the study. Altogether, 11 suitable candidates were enrolled for the study through a purposive sampling.

Four of them were hospital unit incharges, two of them were ward staffs and three of them were nurse administrators of different organizations from Kathmandu valley and two participants were nurse teachers.

After approval from the nursing department and Institutional Research Committee Kathmandu University School of Medical sciences (IRC-KUSMS), an open face-to-face and exploratory individual interview method was used for the study. The interviews lasted 50-70 minutes. In interview, audiotape was used for information collection with obtained verbal consent from participants. The interview was conducted till data saturation was reached. Each participant was given a pseudonym number (1-11) instead of their names to keep their information confidential. Open-ended questions were used which focused on understanding of professional development, current needs for professional development in Nepal, barriers for nursing development and the key players who could play big roles in the development.

The study was followed by focus group discussions (FGD) to collect wider ideas, and comments in the study subject. A total three focus group discussions with six participant nurses in each were done in two different hospitals, Tribhuban University Teaching Hospital, Maharajgunj, Kathmnadu and Kathmandu University Hospital, Dhulikhel, Kavre with permission from the concerned nursing authorities. Observational notes were also taken during the discussion.

The interviewer tried to remain non-judgmental, faithful, and respectful of the commitment to confidentiality for maintaining responsible research role while obtaining data and data analysis. Trustworthines and data credibility were established via face to face discussion with the participants during interview and FGD. Two senior nurses had reviewed the data as a peer reviewer and group discussion was done to reach the final agreement of result.

Immediate notes were made after the interview and FGD, which included comments and significance of data. Listening to the tape, the contents were transcribed into meaningful data. These data were also compared with the notes taken for part of the words, phrases and non-verbal communications.

Qualitative content analysis discussed by Granehein and Lundham ${ }^{6}$ was used for the analysis. Three levels of coding was selected for the data coding. Level I coding examined the data line by line and made codes which were taken from responses of the subjects. Level 2 included coding and comparing of coded data with other data and creating catagories. Catagories were coded data that made group together and result from the condensing of level 1 code.

\section{RESULTS}

There were eleven female, nurse participants, aged between 25-50 years with service experience ranging from six to twenty eight years. All of them were licensed from Nepal Nursing Council.

The content analysis led to five themes. From the participants view points, "continuing professional development (CPD)", "supportive management", " nursing leadership" "recognition and respect", , and "professional networking" were important for nursing professional development in Nepal.

\section{Continuing professional development}

Continuing professional development emerged from all the interview participants. All of them felt nursing curriculum should be revised, four of them felt that the traditional nursing roles need to be reassessed, another stated that the nurse's quality of practice and skills need to be developed by training, and providing facilities for further education. Two of them expressed requirement of more theory with practical training in the nursing education. One of the senior nurse managers expressed the need of more and more researches in the nursing field and capacity building in the concern practice area. Major views were:

"...revision of the curriculum..."

"...traditional roles in nursing need to be changed ..."

"...more theory with the practical..."

“...training in different specialty for the capacity building and team bulding ..."

"...research and capacity building is needed for professional development..."

Supportive Management 
Shrestha et al. Nurses' Views on Need for Professional Development in Nepal

Another major theme extracted from the interviews was need of 'supportive management or support from the institute and nursing department itself'. All participants stated adequate motivation was needed for development in the profession. One of the participants expressed that there is need of proactive planning for professional development. Similarly, the other argued that autonomy at work place is crucial for nurses, which would make nurses more accountable and responsible. One of the younger participants said that senior nurses need to give time for training and building young nurses. Likewise, another participant expressed that only with equal rights in the resources and management can there be proper development. In addition, one senior participant shared that she feels need of male participation in nursing profession, which is also a part of professional development. Another participant felt that clinical nurses are overloaded and their work hours needed to be reassessed. Some of the repeated expressions were:

“.....working environment should be comfortable and encouraging....."

“....equal participation and distribution /systematic rules and regulation...."

"......nursing standard in practice...."

“....professional rules and regulations should be obeyed by each nurse...."

All of them agreed that nurses themselves are responsible for their development. The others felt the employers, organization chiefs, Nursing Association of Nepal (NAN) have major responsibilities. Many participants stressed that their employers needed to be nurses' friendly for the quality health service.

\section{Nursing Leadership}

All the participants expresed need of "nursing leadership" for the professional dvelopment in nursing. Six of them shared nursing leaders need to be non-political and unbiased. Two of them expressed their manager need to be role model and leader for quality nursing service. One of them maintained strong need of visionary leader in nursing. One of the participants also expressed managers need to develop leadership qualities to move from the current trends of nursing in Nepal. One of the senior nurse administrator mentioned a visionary leader can transform a profession to explore and move its' way to the highest level.

“... nurse managers need to develop leadership qualities...."

“...nurse leaders need be supportive for the nursing professional development..."
“...I feel nurses need visionary nursing leaders to improve a current professional status..."

\section{Supportive management}

Another major theme extracted from the interviews was need of 'supportive management or support from the institute and nursing department itself'. All participants stated adequate motivation was needed for development in the profession. One of the participants expressed that there is need of proactive planning for professional development. Similarly, the other argued that autonomy at work place is crucial for nurses, which would make nurses more accountable and responsible. One of the younger participants said that senior nurses need to give time for training and building young nurses. Likewise, another participant expressed that only with equal rights in the resources and management can there be proper development. In addition, one senior participant shared that she feels need of male participation in nursing profession, which is also a part of professional development. Another participant felt that clinical nurses are overloaded and their work hours needed to be reassessed. Some of the repeated expressions were:

“.....working environment should be comfortable and encouraging....."

“...equal participation and distribution /systematic rules and regulation...."

“......nursing standard in practice......."

“....rules and regulations should be obeyed by each nurse...."

\section{Recognition and respect}

All of them expressed need of recognition and respect within the nurses themselves and also among the coworkers including doctors, students and even patients. One of them expressed that there is great need of proper placement of the nurses that suit their capacity and level of education. Below are some of the ideas and words that had been repeatedly stressed by the participants of the FGDs.

\footnotetext{
“...should have respect within each other..."

“...should be treated with humanistic..."

“...need to be respected and recognized as a respectful profession ..."
}

"...I feel there is extreme lack of awareness regarding nursing as a profession, therefore, nurses and nursing related organizations need to make effort on quality improvement in nursing service to win public trust and respect..." 
Shrestha et al. Nurses' Views on Need for Professional Development in Nepal

\section{Professional Networking and Teamwork}

The theme professional net-working was extracted from the all the individual interviews. They considered the networking among the nurses increases the professional communication or interaction for development. Seven participants expressed that nurses need to learn from each other. Two of them expressed that connection among nurses will facilitate to support each other to grow. One participant shared that NAN can play an important role for the professional networking among the nurses and outside of the nursing. One of the participants expressed that the time has come to use advance technologies of networking for professional development. Two of them expressed that nurses also need to generate fund for the professional networking for the workshop and conferences for professional development. One of them shared that networking should be inclusive with the nurses from rural area. Below are some of the ideas and words that had been repeatedly stressed by the participants.

"....for me networking is crucial within the professional members for the professional development..."

" .... development is a process it cannot occurs separately, it requires regular and continuous interaction within the professionals and outside of the nursing profession (other disciplines)..."

“....NAN should play facilitating role for the professional development...."

\section{Barriers for the nursing professional development}

Regarding the barriers toward professional development, many participants were concerned about the 'lack of career ladder', which in their view is the link to the access of 'autonomy'. Likewise, 'poor commitment', "lack of supportive leadership" and 'role conflict' were also expressed as major barriers. Some of the repeated expressions were:

"...we have less career ladder; nurses need to work on it..."

"...poor commitment towards the job by the nurses themselves..."

".... female gender bias role, male need to join the profession........"

"...financial support for the continued professional development....."

“...mushrooming of nursing education institutes without quality assessment..."

From the focus group discussion, nurses gave a wide range of responses. They said that there need to be autonomy in nursing, all of the participants agreed that nursing profession need to change current trends to make nursing profession more appealing in Nepal. Followings are the excerpts (citation) from the participants of one of the FGDs:

Nurse 1. Autonomy in the working place is crucial for nurses, which will make nurses more accountable in their responsibility.

Nurse 2. More professional interactions and researches are needed for the nursing profession development.

Nurse 3. More and more theories with practical skills are needed in the practice.

Nurse 4. All nurses are professional therefore they need to provide quality care and quality service they must not do malpractices.

Nurse 5. Nurses can also contribute for the national nursing welfare, if they moved out from the country.

Nurse 5. Men need to be enrolled in nursing profession to come out from the traditional feminist roles of nurses.

Nurse 2. The most important think is quality of nursing intake needed to be control immediately to prevent mushrooming nursing educational institutes.

Nurse 6. Senior nurses need to invest their time in training and capacity building in young nurses.

Nurse 1. It is crucial for the nurses' self respect and dignity. There need to be equal rights in the resources and management for the capacity building.

Nurse 6. Working environment should be safe along with job security.

Nurse 8: Leaders in nursing should have vision and mission and goals for the nursing professional development.

Nurses in the other groups also expressed similar opinions. In one group, a nurse administrator argued that there need to be control over nursing education's quality. One of the young nurses expressed that there should collective networking among nurses.

\section{DISCUSSION}

The study found that "continuing professional development" and "supportive management", "nursing leadership" "recognition and respect" and "professional networking" are the major needs for professional development among nurses in Nepal. In Maslow's human need theory, he identified two types of needs; 
Shrestha et al. Nurses' Views on Need for Professional Development in Nepal

deficiency (physical, safety, belonging and self-esteem) and growth needs (self-actualization). ${ }^{7}$ According to the Maslow's human needs theory the identified all five themes were deficiency needs or below the growth needs for the nursing professional development.

Professional development is a part of moving forward which is not easy to describe or define for any profession. ${ }^{2}$ It has been defined as an advancement of skills or expertise to succeed in a particular profession, especially through continued education and learning. Kamp believes that professional development occurs where professionals see their task in a new light, with the aim of maintaining or improving the quality of performance. ${ }^{8}$ Therefore, professional development in nursing is an important aspect for a countries' at present and future quality health service. International Council of Nurses (ICN) and International Labor Organization also believes that access to continuing education and career development and professional development is critical and is a fundamental workers right. ${ }^{5-9}$

Continuing professional development was identified as another theme which was expressed as need of training in different specialties, revision of the curriculum, further study and research skills. Since the majority of the study participants were clinical nurses they felt need of enhancing professional skills. Continuing Professional development means different things to different people. For the most of the professionals, it is learning for the holistic development of professional skills. ${ }^{2}$ It has positive aspects which include job satisfaction, staff retention, clinical supervision and critical thinking specific to practice issues. ${ }^{10}$ This finding is also confirmed by other studies which identified professional development needs are keeping up to date with ongoing advances in nursing practice and learning and meeting the need and demand of the their current roles. ${ }^{11,12}$

Another main theme identified was 'supportive management' for the professional development. According to the participants, adequate motivation, proactive planning, autonomy in the working place, senior nurses giving time for training and building young nurses and equal rights in the resources are required for professional development. They also expressed that they were overloaded and their work hours needed to be reassessed. These finding are near to the finding of several studies. Supervisors who concern themselves with the staff member perception can better identify the support needs of the staffs. ${ }^{13}$ Another study identified that there needs to be a collaborative and collective approach to meet both individual and organizational needs for the professional development ${ }^{14}$ and supportive empowering to the employees increases the care quality. ${ }^{13}$ Likewise, study findings of Adib Hagbaghery et al. also confrimed the need of positive and supportive culture of appreciation in the workplace. ${ }^{15}$ Near to current findings, study found that most nurse leaders did not think strategically in promoting clinical ladders at the organizational level. Nurse leaders who considered clinical ladder as a tool in developing nursing quality found their work challenging and rewarding. ${ }^{16}$ Courtoney $M$ et al. also confirmed professional development of staffs, human resource management, information technology and organization management needs for the professional development. ${ }^{10}$

Another themes emerged from the data was "respect and recognition". Respect and recognitions are basic foundations for a profession and it is also an important need in the nursing profession which enjoys recognition and respect from a wider community. ${ }^{17,18} \mathrm{~A}$ meaningful recognition to the nurses enhance positive outcomes, job satisfaction, and career commitment. ${ }^{19}$ The study findings were also supported by the study done by Ulrich et al. They identified five themes (listen, be fully attentive, and truly hear, treat others as you wanted to be treated, acknowledge and express appreciation, exhibit empathy and understanding, display courtesy and consideration, and be accountable and professional) in describing respect to and from colleagues and four themes from the managers (acknowledge staff, communicate and information exchange, ask staffs for their opinions and for what they need and be supportive, fair, consistent, and empathetic) as important need for the nurses. ${ }^{17}$ Similarly, the American association of Critical care Nurses (AACN) also felt need of recognition. They delineated or outlined meaningful recognition as one of the six essential standards of care. AACN wrote that recognition of the values and meaningfulness of one's contributions to an organization's work is a fundamental human need and essential requisite to personal and professional development for the nurses. ${ }^{20}$

"Professional networking" is one of the theme that emerged from the data. The finding is confirmed by the study by Halcomb et al. which identified more than half of the participants desired to get involved in professional networking and many of them liked multidisciplinary and intersectorial networking for Professional development. ${ }^{21}$ Interdisciplinary team functioning, creating prfoessional strategic alliance needs were also identified as important for the profeesional dvelopment by Miener, Alexzender, Blaha et al. ${ }^{22}$ World Health Organization (WHO) also initiated midwifery and nursing institutions networking to help the member countries to work together for nursing and midwifery development. ${ }^{23}$ Another research suggests that the quality of communication among disciplines is important for achieving of positive outcomes for the nurses. ${ }^{24}$

Several barriers for the professional development 
were extracted from the study: career ladder, poor commitment to the job, labeling nursing as female oriented profession, role conflict and mushrooming of many nursing educational institutes with out meeting quality. This finding has been confirmed by not feeling encouraged for CPD, heavy workload, merging the roles within the job. ${ }^{15}$ Similarly, lack of time, not getting relief from the job, cost, inadequate district and regional support were found as barriers for the professional development. ${ }^{10}$ Likewise, identifying or labeling nursing profession as female job is also a concern for professional development.

This study has diverse participants - some with managerial experience, others with clinical experience, some with less experience some of them with teaching experiences. This diverse nature of the participants ensures views from different levels and aspects.

Similarly, the data from FGD of current study confirmed the most of the findings from the individual interview of current study. Both the individual interview and FGD suggested that CPD needs "supportive management", "nursing leadership", "respect and recognition" and "professional networking". This revealed that nurses strongly feel that professional development is crucial. In both the individual interview and FGD, nurses' described professional development is important from which they can enable themselves to face the current challenges of nursing. In contrast to the data from individual interviews, finding from FGD also revealed the need of "safety and security."

\section{CONCLUSIONS}

"Continuing professional development", "recognition and respect", "nursing leadership", "supportive management" and "professional networking" are the major requirements for professional development among nurses in Nepal. Therefore, for the professional development there should be continued refreshing trainings, recognition and respect from higher authority, distant vision leadership, good support from management section as well as good professional networking.

\section{ACKNOWLEDGEMENTS}

The investigators wish to thank the study participants for their valuable views for this study.

\section{REFERENCES}

1. World Health Organization. Strategic directions for strengthening nursing and midwifery services. Geneva: WHO; 2002

2. Oulton J. International trends in nursing professional development. Int Nurs Rev. 1997;44(2):47-51.

3. Pokhrel T. Nursing Education in Nepal. In: Souvenir. $11^{\text {th }}$ National Nursing Conference; 2009 May 10-11; Kathmandu. Kathmandu: Nepal Association of Nepal; 2009. p. 46-9.

4. Nepal Nursing Council. [Online]. 2010 [Cited 2010 Apr 17]. Available from: http://www.nnc.org.np/index. php?pageid=about_nnc

5. International Nursing Council. [Online]. 2010 [cited 2010 May 30]. Available from: http://www1.icn.ch/PS_C02_Career $\% 20$ Dev.Nsg.pdf

6. Graneheim UH, Lundman B. Qualitative content analysis in nursing research: concepts, procedures and measures to achieve trustworthiness. Nurses education today. 2004;24:10512.

7. Huitt W. Maslow's hierarchy of needs. Educational Psychology Interactive. [Online]. 2010 [Cited 2010 May 14]. Available from: http://www.edpsycinteractive.org/topics/ regsys/maslow.html

8. Kamp C. Community Health Nursing Education: Where we are going and how to get there. Nursing Education Perspective. 2003;24(3):144-50.
9. International Labour Organization. Convention 149 on nursing Personnel. [Online]. 2010 [Cited 2010 May 02]. Available from: http:/ / docs.google.com/viewer?a=v\&q=cac he:N9Xi6CqD2TwJ:www.ilo.org/public/english/dialogue/ sector/publ/health/c149.pdf

10. Courtoney M, Yacpetti J, Cathrine J, Walash A, and Montagomery M. Queenland public sector nurse executives' professional developments needs. [Online]. 2010 [cited 2010 Jun 8]. Available from:http://docs.google.com/viewer?a $=\mathrm{v} \& \mathrm{q}=$ cache:RuamuyeLTpAJ:eprints.qut.edu.au/258/1/ courtney_Queensland.PDF

11. Wood J. Exploring staff nurses views on professional development. Nurs Times. 2006;102(13):36-8.

12. Bibb SC et al. Professional development needs for the Registered nurses Practice at a Military hospital. J Conti Edu in Nurs. 2003;34(1):39-45.

13. Raikkonen O, Perala ML and Kahanpaa A. Staffing adequacy, supervisory support and quality of care in long-term care settings: staff perceptions. J Adv nurs. 2007;60(6):615-26.

14. Kathleen M. Continuing professional development and the charitparadigm: interrelated individual, collective and organizational issues about continuing professional development. Nurse Education Today. 2008;28(8):935-61.

15. Adib MH, Salsali M, Ahmadi F. A qualitative study of Iranian nurses' understanding and experiences of professional power. Human resources for the health. 2004;2:91-114. 
16. Torstad S, Bjork IT. Nurse leaders' views on clinical ladders as a strategy in professional development. J Nurs Manag. 2007 Nov;15(8):817-24.

17. Ulrich B, Breugger R, Leften C. Respect: Beginning to define the concept in nursing. Nursing First. 2009;2(3):3-9.

18. The ultimate destination for nursing information. Is nursing as profession? [Online]. 2010 [Cited 2010 May 27]. Available from: http://www.ultimatenurse.com/nursingprofession/3/

19. Psychological Associates DAISY Foundation. Literature review in meaningful recognition in nursing. [Online]. 2010 [Cited 2010 May 20]. Available from: http://www. daisyfoundation.org/downloads/LiteratureReviewNursing. pdf

20. American Association of Critical-Care Nurses. AACN Standards for Establishing and Sustaining Healthy Work Environments: A Journey to Excellence. American Journal of Critical Care. 2005;14:187-97.
21. Halcomb EJ, Meadley E, and Streeter S. Professional development need of general practice nurses. [Online]. 2010[Cited2010 August 19]. Available from: http://www. contemporarynurse.com/archives/vol/32/issue/1-2/ article/2937/ professional-development-needs-of-general.

22. Misener TR, Alexxender JW, Blaha AJ, Clarke PN, Cover CM, FEiton GM, et al. National Delphi study to ddetermine compitencies for nursing leadership in public health Image. J of Nurs Scholarship. 1997;29(1):47-51.

23. World Health Organization, Regional Office for south East Asia. Networking of Nursing and Midwifery Education Institution for Nursing and midwifery Development. [Online]. 2010 [Cited 2010 August 22]. Available from: $h t t p: / / w w w . s e a r o$. who.int/LinkFiles/Publications_NURS-453.pdf

24. Hall LM. A Study of the Impact of nursing Staff Mix Models and organizational Change Strategies on Patient, System and Nurse Outcomes. J Nurs Manag. 2007 Nov;15(8):817-24. 